\title{
Comparative analysis of large scale scenario-based landslides hazard zonation maps. A case study in Iasi City, Romania
}

\author{
Cristina Magdalena COMAN ${ }^{1}$, Sanda MANEA ${ }^{1}$, Ernest OLINIC $^{1}$, Ioan BOȚI ${ }^{1}$ \\ ${ }^{1}$ Department of Geotechnical and Foundation Engineering, Technical University of Civil Engineering, \\ Bucharest, Romania
}

Received 6 November 2017; Revised 25 November 2017; Accepted 15 December 2017

*Correspondence to: Cristina Magdalena COMAN, e-mail: cristina.coman.m@gmail.com

\begin{abstract}
Large-scale landslides hazard analysis is based, among other methods, on the numerical evaluation of the safety factor using physical and mechanical parameters measured in the field. The safety factor is determined as the ratio between the forces acting in the favor of sliding phenomenon and the resistance of the earthen massive. The main purpose of the paper is to create two bi-dimensional models of landslides hazard assessment based on the estimation of the stability factor, under different degrees of soil saturation and considering different scenarios of seismic acceleration. Slope stability analysis allows the simultaneity of two exceptional loads such as saturation and earthquake. The first model follows the methodology provided by the national law. In this case, the safety factor is determined by applying limit equilibrium methods using specific geotechnical engineering software. The second model aims to create a deterministic model for safety factor assessment implemented in a GIS system. This one is based on the infinite slope model. The secondary objectives of the paper are: providing theoretical principles, attaining the comparative analysis between the methodologies mentioned above, identifying the critical points of the created models and the reciprocal validation of the results. The study area is a hilly area located in the NorthWestern part of the Iasi City, Romania. The geotechnical parameters were obtained from the laboratory tests carried out on samples taken from 22 boreholes. The geomorphological parameters resulted from the high quality digital elevation model with $1 \mathrm{~m}$ resolution. The final maps representing the spatial distribution of the safety factor values are reclassified using a common scale. Similarity analysis of the results indicates a good mutual validation.
\end{abstract}

\section{KEYWORDS}

Landslides; hazard maps; safety factor; limit equilibriaum method; infinite slope model; GIS 


\section{Introduction}

The natural phenomenon of "landsliding" represents the movement of earth mass, rock or shallow debris, along a slope, under the direct influence of gravity (Cruden, 1991; Cruden and Varnes, 1996). The most common factors that act as triggers for landslides are prolonged intense rainfalls, rapid snow melting, earthquake, freeze-and-thaw weathering, floods and anthropogenic activities (a frequent and current cause, but acting mainly as a preparing factor) (Wieczorek, 1996; Crosta and Frattini 2008).

Landslides represent a natural hazard, which in many areas of the world causes economic damage, loss of life and in certain situations proving to be more destructive than other natural hazards (McConnell and Brock, 1904; Heim, 1932; Crozier, 2005; Mandal and Maiti, 2014).

Long term demographic analysis, over a range of about 160 years, shows that Europe's population has grown from about 200 million people, registered in the 1850s to 739 million registered in 2017 (Cameron, 1993; European Statistical SystemEES). In the same period, according to the Romanian National Institute of Statistics, the population of Romania has increased from 4 million (in 1850) to 19 million (in 2017), with the peak of 23 million reached in 1990. The human number growing is inevitably associated with intensive, sometimes excessive, local land exploitation, new housing development and construction of roads, railways and other specific works. The population growth, the expansion of settlements and the mandatory ways of communication have invariably led to landslides triggering and have significantly increased the impact of landslide hazards. Consequently, managing this type of hazard has become a continuing concern of Europe's environmental policies and also of Romania.

Unlike other natural hazards (e.g. floods), systematic investments in structural measures to reduce the landslides risk in very large areas cannot be practically done. For example, to limit floods in hydrographical basin can be implemented structural measures such as flood control dams or long lengths levees. These are hydrotechnical structures which can prove costly, but they have an effect that controls the entire basin. Constructive measures used to combat and stabilize landslides have a local effect, often reducing the risk only on restricted areas, frequently a single slope or a part of the slope. It is therefore extremely difficult, economically speaking, to eliminate the landslides risk in very large areas (such as basins). As a consequence, the solution seems to be the implementation of prediction and prevention systems, as well as land-use planning regulations aimed to avoid costly combating projects. This solution is based on extensive studies for landslides hazard assessments and it is a challenge for scientists and decision-makers and even for concerned citizens.

The hazard cartography should not be perceived as a simple editing process, or as a set of computer tools designed to display information about landslides occurrence, but represents a whole set of theories and methods, patterns and techniques for obtaining, analyzing and generating relevant information intended to the final users.

Large-scale landslides hazard analysis (also called local scale analysis) is achieved in most cases using quantitative methods based on the creation of physical models. These types of hazard assessment involve mathematical modeling of the slope failure mechanism.

The scientific literature shows that the main quantitative methods used at large and very large scale for landslides hazard assessment are the finite element methods (3D), the limit equilibrium (2D) methods and the deterministic methods implemented in geographic information system (2D) (Corominas et al., 2014). The paper follows the application into particular cases of the last two types of methods.

These models have a higher predictive capacity than heuristic and statistical models because they use measurable parameters. The parameters used in the stability models building (geotechnical parameters, morphological parameters, seismic parameters and hydrogeological parameters) are being considered state variables that have a unique value at a given moment in time and space. 
The main indicator that evaluates the steady state of the slope is the safety factor whose physical significance is expressed by comparing the stress states along the potential failure surface as a relation (ratio) between actions and soil resistances. The safety factor can vary between the critical value represented by the minimum value that marks the stable equilibrium limit and large and very large values, theoretically infinite values, when the slope is stable (Manea, 2009).

\section{Natural and anthropic conditions influencing landslide hazard in the study area}

Regional-scale landslides hazard analysis reveals that Iasi City, located in the North-Eastern part of Romania, is an area with medium-high and high potential for landslides occurrence (Coman and Manea, 2017).

The natural landscape of Iasi City is represented by wide interfluves and hilly areas partly affected by erosions and landslides (Adomnitei, 2010). Iasi City is an active morphodynamic area and, sometimes, is affected by landslides with high magnitude and which generates significant damage. Here are presented only few examples (Fig. 1.a.): the Eastern side of the Copou Hill, the segment between Sararie and Ticau, the right bank of the Cacaina River, the Bucium Hill, the Galata and Niculina districts (Adomnitei, 2010).

In the last decades, extensive work has been done to reduce the landslides risk; nevertheless the potential for instability is still high in the Iasi area (Adomnitei, 2010).

\section{Site characterization}

The study area is represented by a hilly area with altitudes between $50 \mathrm{~m}$ and $100 \mathrm{~m}$ (Fig. 1.b.) a.s.l., located in the North-Western part of Iasi City, on the left bank of the Bahlui River. The natural terrain slopes vary between $0^{\circ}$ and $43^{\circ}$ (Fig. 1.c.).

The regional geological map (scale 1:20 000) indicates the presence of the Bessarabian (bs) deposits represented by clays, silty clays, sands and sandy clays. The Bessarabian is known as the oldest deposits in this region and with the widest spread.
The geotechnical characterization of the site resulted from the processing of geotechnical parameters determined in laboratory tests, on samples taken from the 22 boreholes (Figure 2) with $10 \mathrm{~m}$ maximum depths. The groundwater level was intercepted in depths ranging from $5 \mathrm{~m}$ to $7 \mathrm{~m}$.
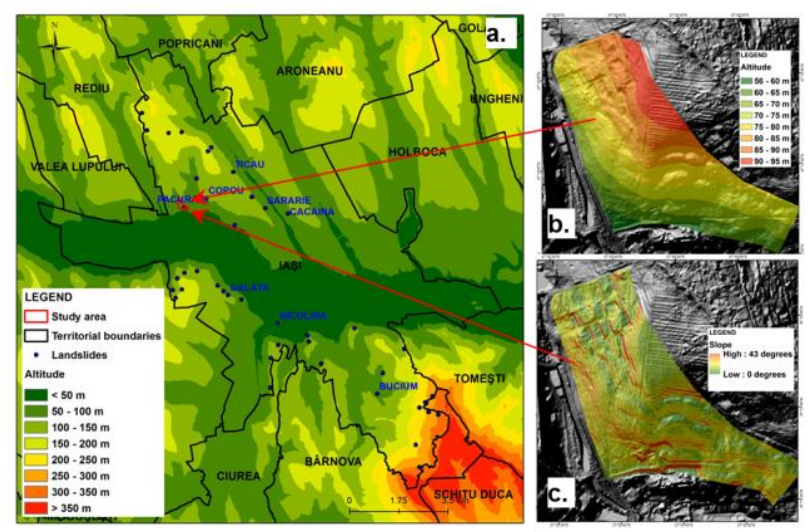

Figure 1 a. Altitude map and historical landslides - Iasi City; b. Altitude map - Study area; c.Slope map - Study area

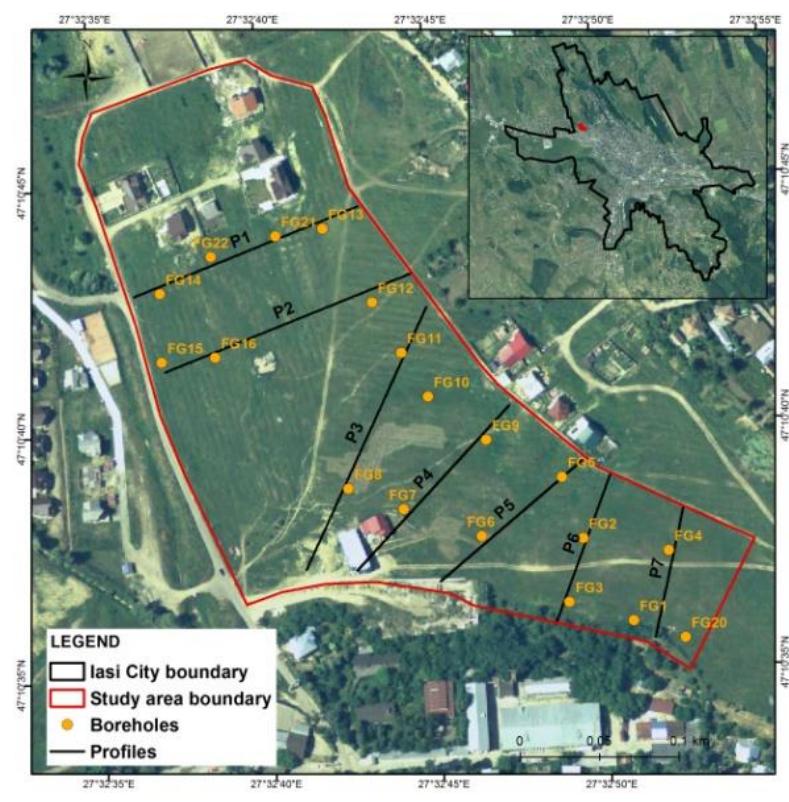

Figure 2 Study area - boreholes location

The general stratification of the earthen massive indicates the overlay of the following layers: under the topsoil layer distinguish a succession of yellow clays, gray clays and brown coal clays, with a lot of sand fractions, which represents a very favorable setting for landslides occurrence. The 
average values of geotechnical parameters that characterize the site are $20 \mathrm{kN} / \mathrm{m}^{3}$ for soil unit weight, $65 \mathrm{kPa}$ for cohesion and $15^{\circ}$ for internal frictional angle.

\section{Data and methodology}

\subsection{Input data}

The database needed to build the two models proposed by this paper consists of morphological data, geotechnical data and seismic data.

The morphological data resulted from the digital elevation model (DEM) made available for this study by the Prut - Barlad Water Basin Administration. The DEM has a pixel resolution of 1 $m$ obtained from LIDAR (Light Detection and Ranging) scanning. The ground physical and mechanical characteristics resulted in laboratory tests on samples extracted from 22 geotechnical boreholes. The ground tests were conducted in the laboratory of Department of Geotechnical and Foundation Engineering from Technical University of Civil Engineering, Bucharest. The seismic activity of the study area is characterized by a peak ground acceleration value of $0.25 \mathrm{~g}$ for earthquakes with the mean recurrence interval 225 years and the control period $0.7 \mathrm{sec}$ (according to the Romanian Seismic Design Code for Buildings - Part I - indicative P 1001/2013).

The model created approaching the national methodology does not require the development of thematic maps in advance, because it is based on the direct calculation of stability on the lithological profiles.

The infinite slope model requires the construction of a series of thematic maps for all the parameters involved in the evaluation of the safety factor. The geomorphological parameters maps (slope map and the trigonometric functions of the slope) derived from digital elevation model using GIS tools. The geotechnical parameters maps (unit weight map, cohesion map, internal frictional angle map) were built interpolating the 22 points of prospects (measured data).

\subsection{The methodology provided by national legislation}

According to the Romanian "Methodological norms regarding the elaboration and content of natural landslides hazards maps" approved by Government Decision no. 447/2003, the construction of detailed maps (large-scale maps) is based on the results obtained from the slope stability numerical modeling using physical and mechanical soil parameters determined in the laboratory tests.

The methodology consists in determining the safety factor on characteristic profiles for an arbitrary number of slip surfaces (usually noncircular slip surfaces) and drawing the safety factor variation diagram along the slope. This model applies Janbu method which is one of the various limit equilibrium method commonly used for slope stability analysis (Janbu 1968, Abramson 2002). This model uses GEOSTRU software for safety factor calculation. The safety factor assessment must be done on an adequate number of characteristic profiles, traced over the entire length and along the slope concerned. In this paper, 7 profiles are analyzed (Fig. 2).

For a high accuracy results, the methodology recommends for boreholes spatial distribution a field layout in maximum distances of $300 \div 500 \mathrm{~m}$. For the stability assessment were used the calculation values of the geotechnical parameters, established according to the Romanian "Normative regarding the determination of the characteristic and calculation values of the geotechnical parameters - indicative NP 122/2010".

The final hazard maps are drawn as an envelope of the minimum safety factor values $\left(F_{s, m i n}\right)$ from the safety factor diagram and reclassified according to the intervals established as the inverse of the average hazard coefficient. The table below shows the classification ranges (Table 1).

The landslides hazard map building main steps are presented below, in the following logic scheme.

\subsection{The infinite slope model}

The infinite slope stability model is a high degree simplified model, which oversees the destabilizing components of gravity in relation with the resistance 
components given by cohesion and friction along a failure plane, considered parallel to the natural ground surface (Fig. 4). The model accounts for different trigger factors such as the transient groundwater response of the slopes and/or the effect of earthquake excitation.

Table 1 Classification ranges of safety factor

\begin{tabular}{|c|c|c|c|c|c|}
\hline Zero & Low & Medium & $\begin{array}{c}\text { Medium - } \\
\text { High }\end{array}$ & High & $\begin{array}{l}\text { Very } \\
\text { High }\end{array}$ \\
\hline \multicolumn{6}{|c|}{ Average hazard coefficient $\left(K_{m}\right)$} \\
\hline $\begin{array}{c}< \\
0,30\end{array}$ & $\begin{array}{c}0,31 \\
\div \\
0,40\end{array}$ & $\begin{array}{l}0,41 \div \\
0,50\end{array}$ & $0,51 \div 0,60$ & $\begin{array}{c}0,61 \\
\div \\
0,80\end{array}$ & $\begin{array}{c}0,81 \div \\
1\end{array}$ \\
\hline \multicolumn{6}{|c|}{ Safety factor $\left(F_{s}\right)$} \\
\hline $\begin{array}{c}> \\
3,33\end{array}$ & $\begin{array}{c}3,33 \\
\div \\
2,5\end{array}$ & $2,5 \div 2$ & $2 \div 1,66$ & $\begin{array}{c}1,66 \\
\div \\
1,25\end{array}$ & $\begin{array}{c}1,25 \div \\
1\end{array}$ \\
\hline
\end{tabular}

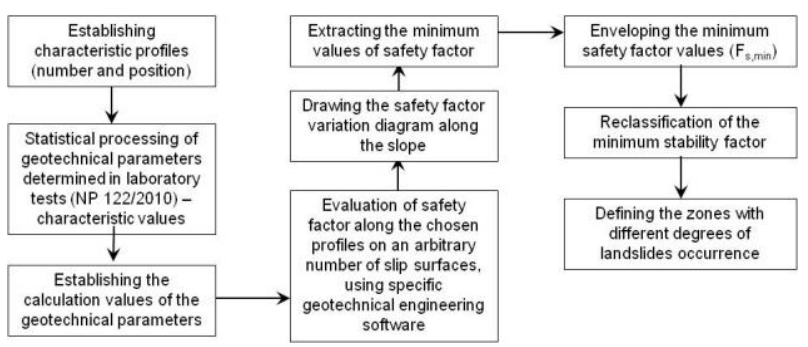

Figure 3 Landslides hazard map main steps - National methodology

The infinite slope model calculates the safety factor according to Equation 1 (Brunsden and Prior, 1984).

$$
F_{s}=\frac{c^{\prime}+\left(\gamma-\frac{z}{z_{w}} \gamma_{w}\right) z \cos ^{2} \beta \tan \phi^{\prime}}{\gamma \sin \beta \cos \beta}
$$

Where:

$c^{\prime} \quad$ effective cohesion $(\mathrm{Pa})$;

$\phi^{\prime} \quad$ effective internal friction angle $\left({ }^{\circ}\right)$;

$\gamma \quad$ unit weight of soil $\left(\mathrm{N} / \mathrm{m}^{3}\right)$;

$\gamma_{w} \quad$ unit weight of water $\left(\mathrm{N} / \mathrm{m}^{3}\right)_{i}$

$z \quad$ depth of slip surface $(m)$;

$z_{w} \quad$ groundwater table height above slip surface $(\mathrm{m}) ;$

$\beta \quad$ terrain slope $\left({ }^{\circ}\right)$.
Under seismic loads the mathematical formula proposed for safety factor evaluation is given by Equation 2 (Brunsden and Prior, 1984).

$$
F_{s}=\frac{c^{\prime}+\left(z \gamma \cos ^{2} \beta-z \rho \alpha \sin \beta \cos \beta-z_{w} \gamma_{w} \cos ^{2} \beta\right) \tan \phi^{\prime}}{\gamma z \sin \beta \cos \beta+z \rho \alpha \cos ^{2} \beta}
$$

Where:

$\rho \quad$ bulk density $\left(\mathrm{kg} / \mathrm{m}^{3}\right)$;

$\alpha \quad$ peak ground acceleration $\left(\mathrm{m} / \mathrm{s}^{2}\right)$.

This model builds safety factor maps considering the following assumptions:

$>$ the geotechnical (physical-mechanical soil parameters) and morphological parameters are the ones that determine the construction of the model and they are most often measurable;

$>$ it can be applied on relatively limited areas when the geological and geotechnical conditions can be considered relatively homogeneous;

$>$ it is intended to be used for shallow landslides (less than a few meters in depth), generally for translational sliding (not for deep-seated landslides types, rock falls, debris flows etc.)

$>$ the two-dimensional model divides the analysis range into discrete elements of the pixels size;

$>$ the effect of the neighboring pixels (the edge effects) is ignored.

\section{Results}

The large - scale landslides hazard models were designed considering four scenarios: completely dry conditions, saturated conditions, completely dry conditions and seismic loads, saturated conditions and seismic loads. The following maps will present each of the four scenarios for both models.

\subsection{Scenario 1 - Spatial distribution map of the safety factor considering dry conditions}

The assessment of the safety factor using the national methodology is done for 7 lithological profiles. The results of the characteristic profile P1 are presented as examples. The safety factor assessment for the other 6 profiles is made following the similar procedure of $\mathrm{P} 1$, according to the steps presented in Fig. 3. 


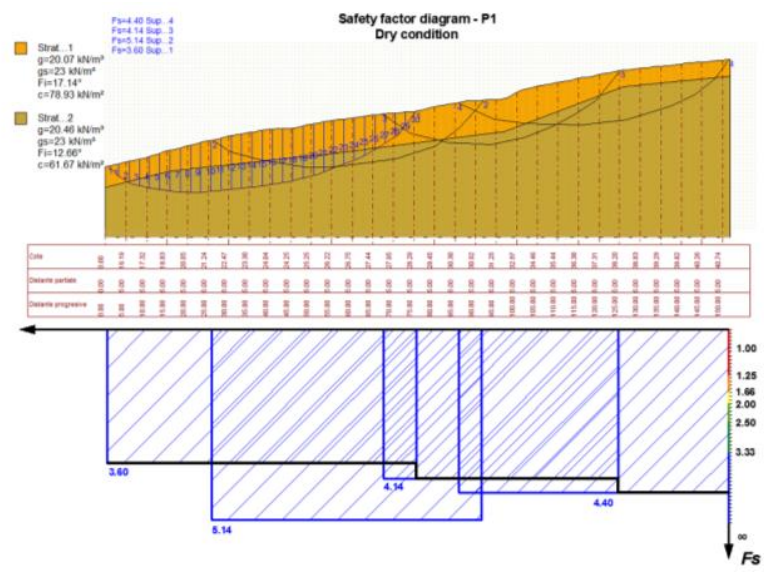

Figure 4 Safety factor diagram, P1 - Dry conditions

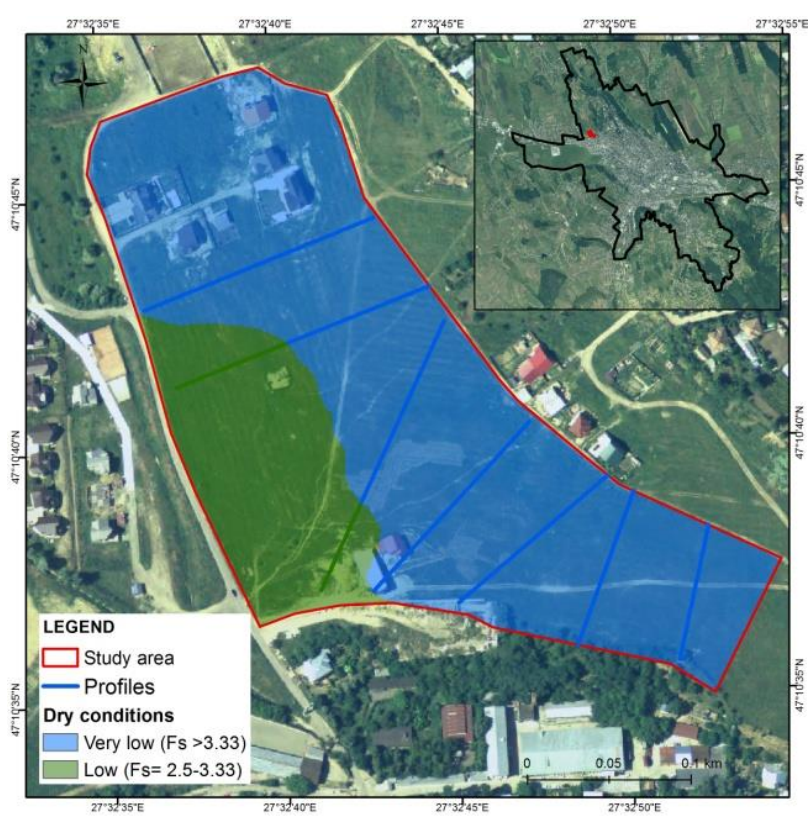

Figure 5 Landslides hazard map, dry conditions - National methodology

Stability factor values (which were greater than 3 for all the 7 profiles) indicate low and very low potential for landslides occurrence.

In the infinite slope model, the safety factor is assessed on the assumption that the soil is completely dry, so the groundwater action is equivalent to 0 . The term $z_{w}$ from Equation 1 is equal to 0 . For each term of Equation 1 parametric maps are constructed and overlapped in GIS systems according to the mathematical formulas provided. The final hazard maps are obtained using the same reclassification system adopted by the previous method.

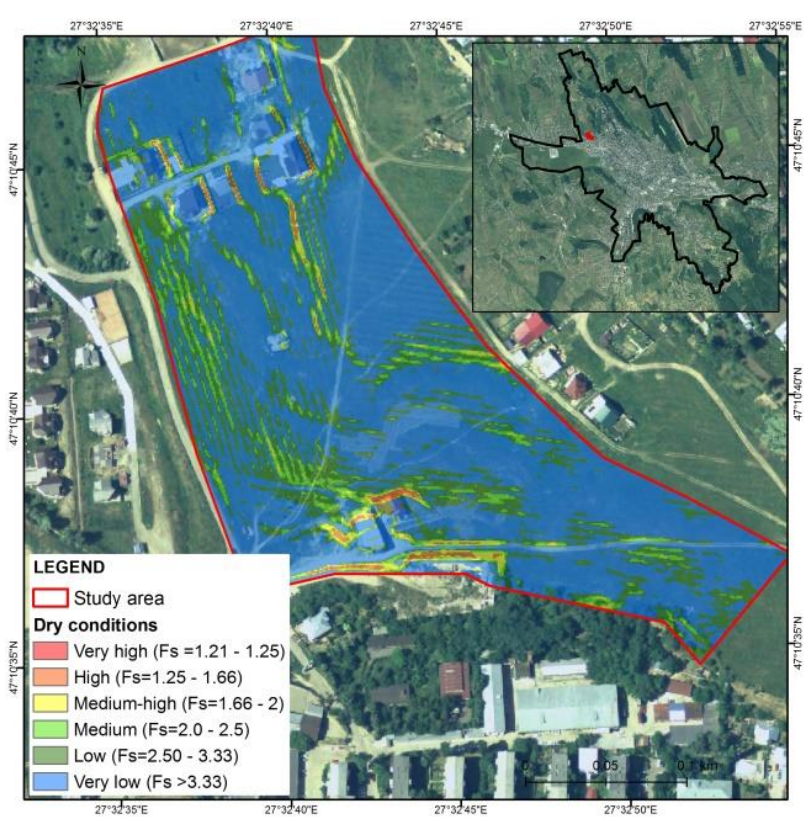

Figure 6 Landslides hazard map, dry conditions - Infinite slope model

This scenario is the most optimistic situation. The study area proves to be generally stable for both models with relatively minor unstable areas for the infinite slope model.

\subsection{Scenario 2 - Spatial distribution map of the safety factor considering saturated conditions}

The ground saturation conditions led to a decrease of the stability factor to 2,8 (the minimum value). This translates into a slight increase in the potential of instability, but it still remains low.

The second scenario assumes that the terrain is completely saturated. In this case, the infinite slope model considers the term $z_{w}$ equal to the term $z$ from Equation 1. It is noticed that the presence of groundwater produces a slight increase of instability potential zones compared to the previous scenario. Comparatively with the previous model results, for the same scenario, the infinite slope model indicates increasing areas with high and very high instability potential. This may be a consequence of the high degree of simplification of failure mechanism. The 
infinite slope model overestimates the safety factor. The minimum safety factor decreases to 0.97 .

Also, the very good resolution of the digital elevation model is important. If the work would not have been done with a high precision model, it is possible that these high-potential areas do not appear or be very small.

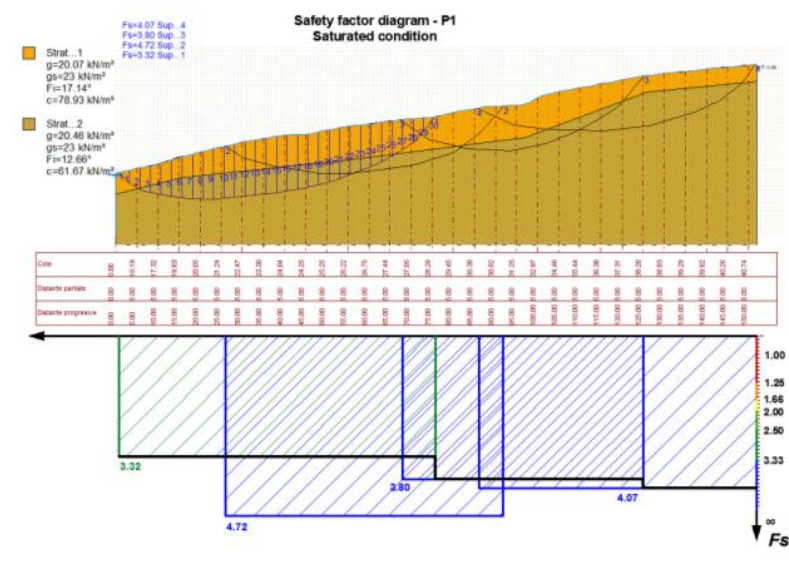

Figure 7 Safety factor diagram, P1 - Saturated conditions

\subsection{Scenario 3 - Spatial distribution map of the stability factor considering dry conditions and seismic action}

The third scenario studies the influence of the seismic activity on the stability of slopes. The occurrence of geodynamic loads shows a significant decrease of the safety factor. The safety factor diagrams for all the 7 calculation profiles indicate minimum values of 1.29 .

For the third scenario, dry ground conditions and seismic loads are considered. For each term of Equation 2 parametric maps are created and overlapped in GIS systems according to the mathematical formulas provided in the previous chapter. The seismic actions correspond to the peak value of the seismic acceleration that characterizes the site. This scenario proves more detrimental than the saturated scenario under static conditions, for national methodology based model and also for infinite slope model. The instability areas have increased considerably.

Applying the infinite slope model, in this scenario, it is noted that the minimum value decreases to 0.91 , but there is also noticed a considerable extension of the areas with high potential for sliding.

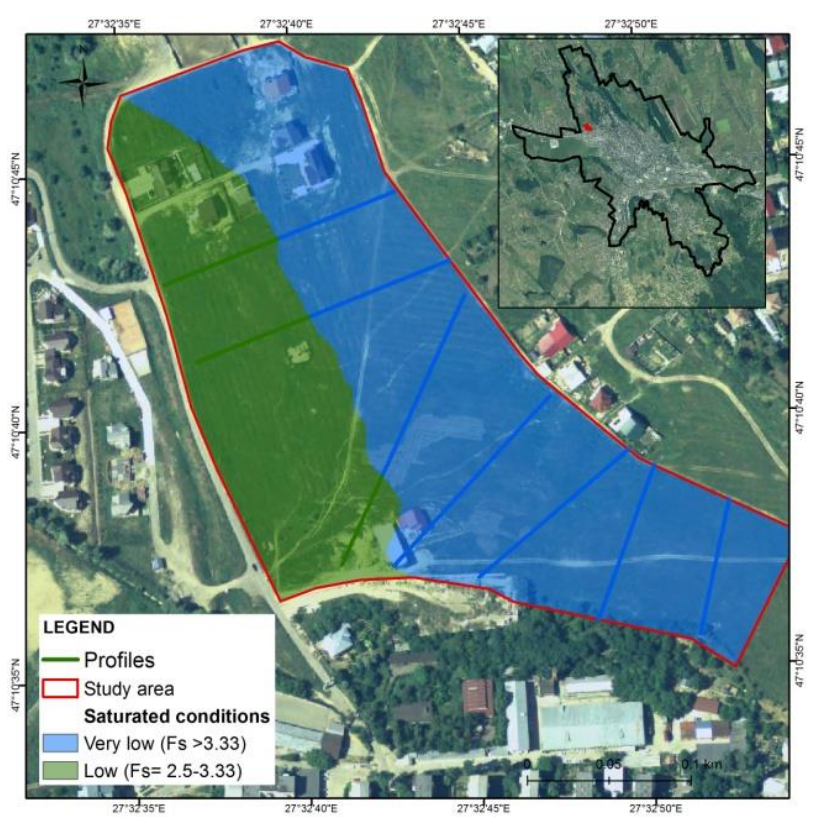

Figure 8 Landslides hazard map, saturated conditions National methodology

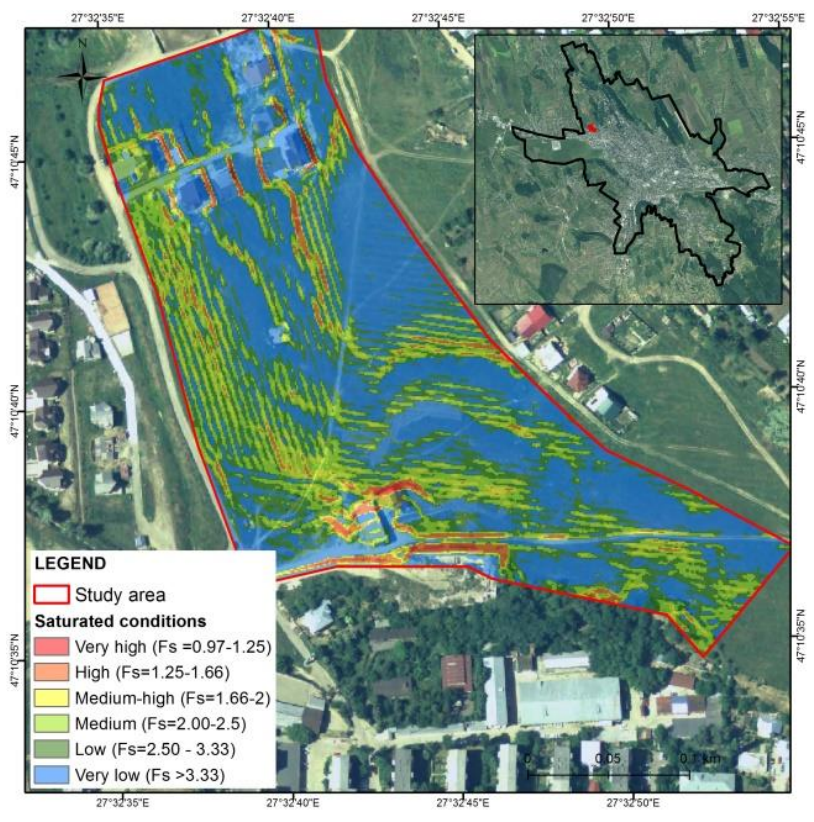

Figure 9 Landslides hazard map, saturated conditions Infinite slope model 


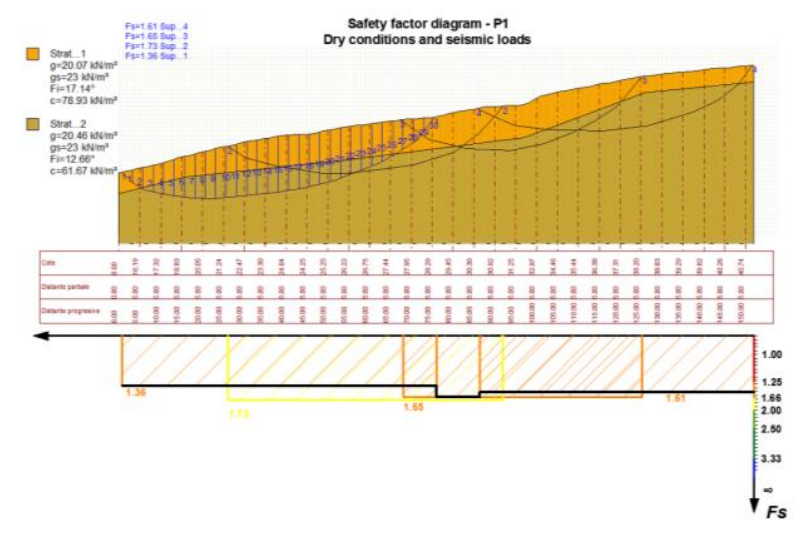

Figure 10 Safety factor diagram, P1 - Dry conditions and seismic loads

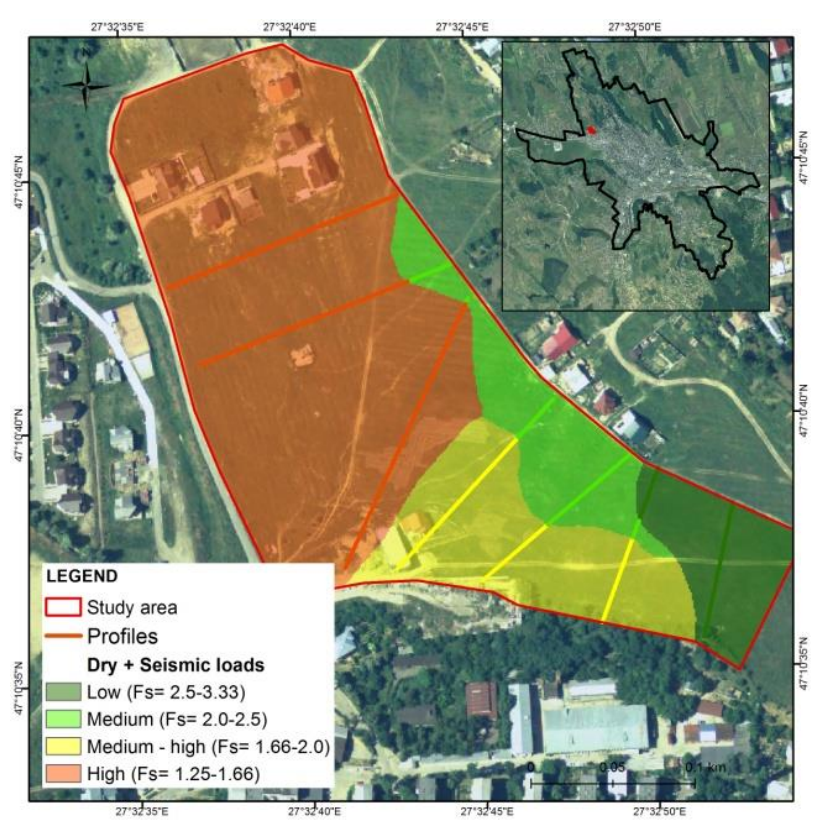

Figure 11 Landslides hazard map, dry conditions and seismic loads - National methodology

\subsection{Scenario 4 - Spatial distribution map of the safety factor considering saturated conditions and seismic action}

Unlike the design of structures, in the slope stability calculations, the simultaneity of two exceptional actions such as those considered in this scenario is accepted.

Applying the national methodology the results indicate a decrease in the stability factor values below the limit of 1,25 and this indicates the occurrence of areas with very high potential for landslide occurrence. The most unfavorable slip surfaces have been identified along the P2 profile, for all the four scenarios.

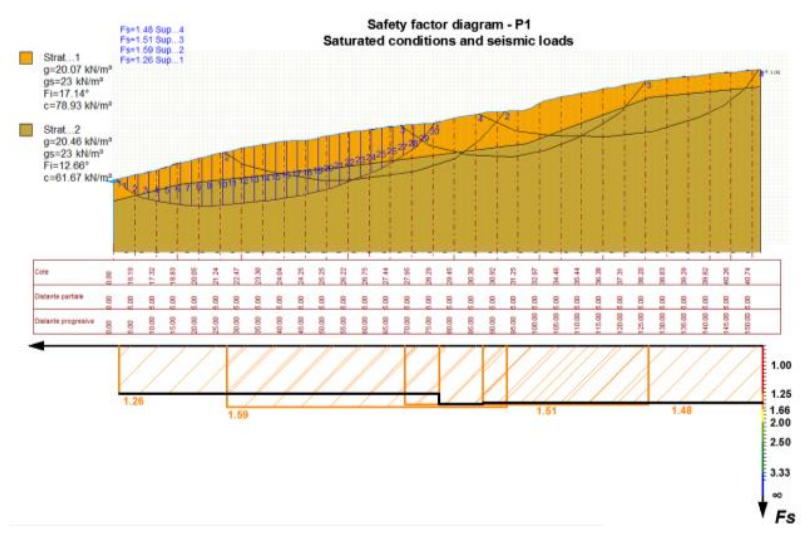

Figure 13 Safety factor diagram, P1 - Saturated conditions and seismic loads

For this scenario, the instability potential is generally large and very high.

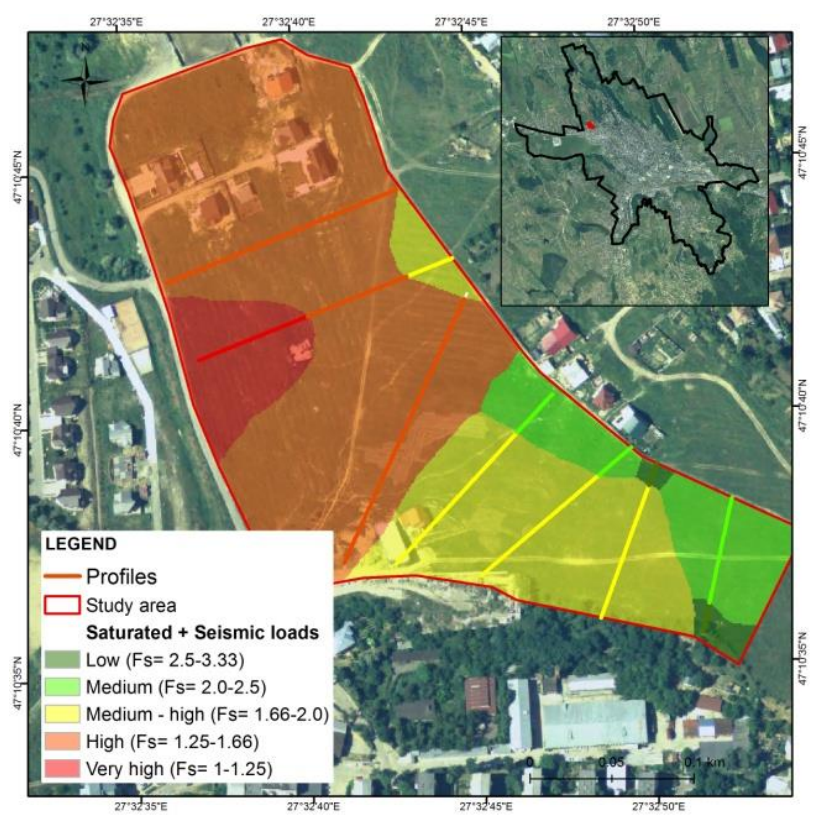

Figure 14 Landslides hazard map, saturated conditions and seismic loads -National methodology

The last of the four scenarios, approached also in the infinite slope model, considers that the soil is under saturated conditions and under seismic loads associated with the peak value of the seismic ground acceleration. In this case, the safety factor reaches the minimum value of 0.75 and the areas 
with very high instability potential signal an important extension in the study area.

\section{Discussions}

The similarity analysis indicates a good mutual validation of the two deterministic models created for the large scales landslide hazard assessment. The four scenarios considered are extreme situation and may not occur in region such as Iasi City but give the most optimistic and the most pessimistic situations.

The hazard assessment methods used to conceive these mathematical models, one with respect to each other, provide a number of critical points.

The model created using national methodology calculates the safety factor using specific geotechnical methods and engineering software, while the infinite slope stability model provides a high degree simplified model of slope failure mechanism applied in geographic systems. Multilayered and non-homogeneous layer evaluations are allowed by the national methodology while the infinite slope stability model is suitable for stratifications in which geological and geotechnical conditions can be considered relatively homogeneous.

The analysis range is meshed into slices (vertical discretization) by the national methodology while the analysis range is meshed into pixels size elements ( $1 \mathrm{~m}$ horizontal discretization) by the infinite slope model. It can be noticed that the infinite slope model achieves a finer safety factor spatial distribution. The accuracy of the results obtained using the national methodology is closely related to the density of the geotechnical boreholes while the infinite slope model is directly dependent on the digital terrain model resolution.

The execution of a large number of geotechnical boreholes but also obtaining a digital terrain model with very good resolution can sometimes prove economically inaccessible. This is one more reason which justifies why these analyzes are suitable for local scales.

Observing these cumulative critical points, it can be concluded that from a scientific point of view, the national methodology has important advantages to the detriment of the infinite slope model.

The landslides hazard maps generates relevant information on landslides and provides certain net benefits, knowing that the risk will be properly controlled, kept under review, and further reduced as and when possible. The ultimate goal of large scale hazard maps is to be introduced and taken into account in development plans, so the assessing of landslides hazard and risk levels is a scientific and technical process as much as a political and economical decision-making process.

The input data underlying such analyzes may prove costly in both cases, requiring high precision. Although it achieves an overstatement of the safety factor, the infinite slope model proves more accessible. Consequently, the end users may feel attracted by the approach of the infinite slope model that can be implemented easily in geographic information systems. Obtaining geotechnical data, required by the national methodology, is a long process through field sampling, laboratory testing and then data processing, costly as the number of boreholes increases.

\section{Conclusions}

The landslides hazard assessment models, similar to those created in this paper, have higher prediction capability than other qualitative or quantitative methods, for example statistical methods, because it evaluates the potential slip following a calculation based on the parameters measured in the field, while the other quantitative methods are based on historical data (landslides inventories).

The landslides hazard assessment based on the stability factor is preferably to be used for local analyzes. It can hardly be applied at national scales due to the variability of geotechnical data and the difficulty of building a national geotechnical database with high precision.

The safety factor maps keep the purpose and the quality of the hazard maps and will not serve the constructions design activities but can serve for prediction and prevention plans.

All the conclusions set out in the paper are the results on the landslides hazard assessments within 
the Iasi City, located in the north-west of Romania. However, the selected examples and the lessons learned are general and applicable in other areas in Romania or even in other countries facing the same situations.

\section{Acknowledgments}

The geotechnical data were obtained in the laboratory of the Department of Geotechnical and Foundation Engineering from Technical University of Civil Engineering, Bucharest and the digital terrain model with $1 \mathrm{~m}$ resolution was made available by the Prut - Barlad Water Basin Administration.

\section{References}

Abramson LW. 2002. Slope stability and stabilization methods. Wiley, New York

Adomniţei, C. 2010. Fundamentarea deciziilor de dezvoltare urbană pe baza hărților de hazard la alunecare, Universitatea Tehnică "Gheorghe Asachi" din Iași, Teză de doctorat

Brunsden D, Prior DB. 1984. Slope instability, Earth Surface Processes and Landforms, Vol.11, Issue 2: 230-231

Cameron R. 1993. Concise Economic History of the World, New York: O.U.P., p. 193

Coman CM, Manea S. 2017. Landslides hazard assessment using different approaches, Scientific Journal Mathematical Modeling, Vol. 13, No 2, pp. 1-16

Corominas J, van Westen CJ, Frattini P, Cascini L, Malet JP, Fotopoulou S, Catani F, Van Den Eeckhaut $M$, Mavrouli O, Agliardi F, Pitilakis K, Winter MG, Pastor M, Ferlisi S, Tofani V, Herva's J, Smith JT. 2014. Recommendations for the quantitative analysis of landslide risk, Bulletin of Engineering Geology and the Environment, Vol. 73, No 2: 209-263

Crosta GB, Frattini P. 2008. Rainfall-induced landslides and debris flows. Hydrol. Process. 22(4): 473-477

Crozier MJ. 2005. Multiple occurrence regional landslide events in New Zealand: hazard management issues. Landslides 2:247-256
Cruden DM. 1991. A very simple definition for a landslide. IAEG Bulletin, pp 27-29

Cruden DM, Varnes DJ. 1996. Landslide types and processes. In: Turner AK, Schuster RL (eds) Landslides. investigation and mitigation (Special Report). Washington, DC, USA: National Research Council, Transportation and Research Board Special Report 247, pp 36-75

European Statistical System-EES, http://ec.europa.eu/eurostat/

Heim A. 1932. Landslide and human life. Fretz and Wasmuth, Zurich

Janbu N. 1968. Slope stability Computations, Soil Mechanics and Foundation Engineering Report, The Technical University of Norway, Trondheim

Mandal S, Maiti R. 2014. Semi-quantitative Approaches for Landslide Assessment and Prediction, University of Melbourne, p 4-5;

Manea S. 2009. Evaluarea riscului de alunecare a versantilor, Edit. Conpress, Bucharest

McConnell RG, Brock RW. 1904. Report on the great landslide at Frank, Alberta, Canada Department of the Interior, Annual Report vol. 1902-1903 no. VIII

Normative regarding the determination of the characteristic and calculation values of the geotechnical parameters - indicative NP 122/2010

Romanian Methodological norms regarding the elaboration and content of natural landslides hazards map approved by Government Decision no. 447/2003;

Romanian National Institute of Statistics http://www.insse.ro/

Romanian Seismic Design Code - Part I - Design provisions for buildings- indicative P 100-1/2013)

Van Westen CJ. 2013. Remote Sensing and GIS for Natural Hazards Assessment and Disaster Risk Management. In: Treatise on Geomorphology ed. by John F. Schroder and M.P. Bishop. San Diego, Academic Press, Elsevier, pp. 259-298

Wieczorek GF. 1996. Landslide triggering mechanisms. In: Turner AK, Schuster RL (eds) Landslides: investigation and mitigation (Special Report). National Research Council, Transportation and Research Board Special Report 247, Washington, D.C., USA, pp 76-90 